\title{
BMS-182123, a Fungal Metabolite that Inhibits the Production of TNF- $\alpha$ by Macrophages and Monocytes
}

\author{
Glenn A. Warr, Judith A. Veitch, Ann W. Walsh, Grace A. Hesler, Dolores M. Pirnik, \\ John E. Leet, Pin-Fang M. Lin, Ivetta A. Medina, Kimberly D. McBrien, \\ Salvatore Forenza, Junius M. Clark and Kin Sing Lam* \\ Bristol-Myers Squibb Pharmaceutical Research Institute, \\ 5 Research Parkway, Wallingford, Connecticut 06492, U.S.A.
}

(Received for publication August 30, 1995)

\begin{abstract}
A fungal metabolite, BMS-182123, which inhibited bacterial endotoxin-induced production of tumor necrosis factor (TNF- $\alpha$ ) in murine macrophages and human peripheral blood monocytes (in vitro), was isolated from the culture broth of Penicillium chrysogenum strain V39673. The effective BMS-182123 concentration $\left(\mathrm{IC}_{50}\right.$ ) resulting in $50 \%$ inhibition of lipopolysaccharide-induced TNF- $\alpha$ production in murine macrophages and human monocytes was $600 \mathrm{ng} / \mathrm{ml}$ and $4.0 \mu \mathrm{g} / \mathrm{ml}$, respectively. BMS-182123 suppressed the lipopolysaccahride-induced TNF- $\alpha$ promoter activity and did not affect the stability of posttranscriptional mRNA. Addition of hydrophobic resin, Amberlite XAD-8 (1\%), to the fermentation enhanced the production of BMS- 182123 by 5.5 fold. A total of $577 \mathrm{mg}$ pure BMS-182123 was recovered from a 250-liter fermentation supplemented with 1\% Amberlite XAD-8.
\end{abstract}

Tumor necrosis factor (TNF- $\alpha$ ) is a pleiotropic cytokine produced primarily by monocytes/macrophages ${ }^{1,2)}$. Unrestricted TNF- $\alpha$ production can lead to the induction of physiological shock. Lipopolysaccharide (LPS), which is present on the outer membrane of Gramnegative bacteria, is the most potent inducer of TNF- $\alpha$ production $^{3,4)}$ and is one of the primary mediators in the cascade of inflammatory events resulting in endotoxic shock and death ${ }^{5}$ ). Therapeutic products under development for controlling the adverse effect of TNF- $\alpha$ include inhibitors, monoclonals, soluble receptors, immunoconjugates and immunomodulators ${ }^{6,10 \sim 13)}$. In the course of our search for microbial metabolites that inhibit bacterial endotoxin-induced production of TNF- $\alpha$ in murine macrophages and human peripheral blood monocytes, an active fungal metabolite was isolated from the culture of Penicillium chrysogenum strain V39673. In this paper, we report the taxonomy of the producing organism, fermentation, isolation and biological activities of BMS-182123.

\section{Materials and Methods}

\section{Fermentation}

For production of BMS-182123 in shake flask culture, $4 \mathrm{ml}$ of the frozen stock of strain V39673 was used to inoculate a $500-\mathrm{ml}$ Erlenmeyer flask containing $100 \mathrm{ml}$ of vegetative medium consisting of $0.5 \%$ soluble starch, $0.5 \%$ glucose, $0.1 \%$ fishmeat extract, $0.1 \%$ yeast extract, $0.2 \% \mathrm{NZ}$-case, $0.2 \% \mathrm{NaCl}$ and $0.2 \% \mathrm{CaCO}_{3}$. The seed culture was incubated at $28^{\circ} \mathrm{C}$ on a rotary shaker set at $250 \mathrm{rpm}$. After 3 days, 4-m1 aliquots of this seed culture were transferred to $500-\mathrm{ml}$ Erlenmeyer flasks containing $100 \mathrm{ml}$ of the production medium composed of $2 \%$ glucose, $1 \%$ cornsteep liquor and $0.5 \% \mathrm{CaCO}_{3}$. The production cultures were incubated at $28^{\circ} \mathrm{C}$ and $250 \mathrm{rpm}$ for 3 days. For production in fermentor seed culture was inoculated into the production tank to yield a final concentration of $4 \%(\mathrm{v} / \mathrm{v})$. Polypropylene glycol P-2000 was used as antifoam. The fermentation was carried out for $3 \sim 6$ days under the following conditions: temperature, $28^{\circ} \mathrm{C}$; agitation, $250 \mathrm{rpm}$; and airflow, $0.9 \mathrm{vol}$. per minute.

\section{Extraction and Analytical Method}

At various times during the production cycle, aliquots of the culture broth was removed from the fermentation and mixed with an equal volume of butanol for 1 hour. After centrifugation, the butanol fraction was concentrated 10 fold and the production of BMS-182123 was monitored by HPLC using a C-18 $\mu$ Bondapak column $(3.9 \times 300 \mathrm{~mm}$, Waters Associates $)$ and UV absorption at $254 \mathrm{~nm}$. The solvent system was $0.1 \%$ $\mathrm{H}_{3} \mathrm{PO}_{4} / \mathrm{CH}_{3} \mathrm{CN}(35: 65)$ with a flow rate of $1.5 \mathrm{ml} /$ minute.

\section{LPS Activation of the Human TNF- $\alpha$ Promoter}

The assay for the human TNF- $\alpha$ promoter activity was a modification of the protocol described by J. S. ECONOMOU et al. ${ }^{14)}$. A sequence of the human TNF- $\alpha$ promoter was excised (EcoR1/AhaII restriction sites) from a human TNF- $\alpha$ genomic clone, using standard laboratory methods ${ }^{15)}$, to yield a 714 bp sequence (which 
included 623 bp upstream and 91 bp downstream to the transcription start site). This promoter sequence was ligated to a luciferase reporter gene ${ }^{15)}$. The resultant plasmid construct was co-transfected into the murine macrophages cell line RAW264.7 (ATCC culture collection) with a second plasmid $\mathrm{pSV} 2_{\text {neo }}$ containing the neomycin resistance gene. The cells were cultured in DULBECCO's modified medium containing 5\% fetal calf serum (Hyclone) and buffered to $\mathrm{pH} 7.4$ with $25 \mathrm{~mm}$ Hepes (DMEM). Colonies positive for the neomycin resistance gene were selected in the presence of the antibiotic G418 $(600 \mu \mathrm{g} / \mathrm{ml})$. Cultures responding to Gram negative bacterial LPS (Escherichia coli 0127 : B6, Westphal extraction; Difco) challenges by producing luciferase were subcultured and stored frozen under liquid nitrogen.

For analysis of the human TNF- $\alpha$ promoter activity, the macrophages were plated overnight at $1.5 \times 10^{5}$ cells/ well in a Costar 48-well cluster dish using $0.5 \mathrm{ml}$ DMEM medium containing G418 $(180 \mu \mathrm{g} / \mathrm{ml})$. Stock solutions $(0.156 \sim 5 \mathrm{mg} / \mathrm{ml})$ of BMS-182123 were prepared in DMSO. A stock solution of LPS was prepared at $20 \mu \mathrm{g} / \mathrm{ml}$ in DMEM. One $\mu$ l volumes of the various BMS-182123 stock solutions were added to triplicate cultures of the RAW macrophages followed immediately by addition of $0.5 \mathrm{ml}$ LPS stock solution. One $\mu 1$ of DMSO was added to cultures as a solvent control, with and without the addition of LPS. For monitoring the active component during fermentation and isolation, $1 \mu \mathrm{l}$ of fermentation extract or solution of partially purified materials was added to the culture in a similar manner as BMS-182123. Cultures incubated in the absence of LPS served as controls for the baseline expression of TNF- $\alpha$ promoter activity. Cultures incubated with LPS in the absence of fermentation extract or test compound served as positive induction controls for activation of TNF- $\alpha$ promoter activity. Eighteen to twenty hours after the addition of the LPS to the cultures, the culture supernates were aspirated, the cells lysed and luciferase activity determined using standard methods. Luciferase mediated luminescence was measured in an MGM OptocompII chemiluminometer. Values are expressed as \% Control LPS induced TNF- $\alpha$ promoter activity (luciferase production).

LPS Induction of TNF- $\alpha$ from Murine RAW 264.7 Macrophages

RAW 264.7 macrophages were plated at $5 \times 10^{5}$ cells/ $500 \mu \mathrm{l}$ in Costar 24-well cluster dishes. The cells were cultured in DMEM and treated in the same manner as the promoter based assays. Cultures incubated in the absence of LPS served as controls for baseline expression of TNF- $\alpha$, cultures treated with LPS $(400 \mathrm{ng} / \mathrm{ml})$ alone served as control LPS induced TNF- $\alpha$ activity. Approximately 20 hours after the LPS challenges, the culture supernatant fluids were removed from the cells and assayed for cytotoxicity using the standard L929 fibroblast cytotoxicity assay ${ }^{16)}$. Values are expressed as
$\%$ Control LPS induced cytotoxic TNF- $\alpha$ activity.

LPS Induction of TNF- $\alpha$ from Thioglycolate Elicited Murine Peritoneal Macrophages

To verify that the compound was also active with native macrophages, cultures were established using murine peritoneal macrophages. Outbred Swiss mice $(25 \mathrm{~g})$ were injected (ip) with $2 \mathrm{ml} 4 \%$ brewers' thioglycolate medium (Difco). Four days later, the mice were sacrified and the cells recovered by standard peritoneal lavage techniques ${ }^{17)}$. The cells were washed and plated as described above. Stock $2 \times$ solutions of LPS were prepared at $400 \mathrm{ng} / \mathrm{ml}$ in DMEM. Stock solutions of BMS-182123 $(0.25 \sim 4 \mathrm{mg} / \mathrm{ml})$ were prepared in DMSO. BMS-182123 effect on LPS induction of cytotoxic TNF- $\alpha$ was determined as described above.

\section{LPS Induction of TNF- $\alpha$ from Human Monocytes}

To determine whether BMS-182123 was active with human monocytes, cultures were established using enriched peripheral blood monocytes. Normal human blood was collected in heparin solution. Mononuclear leukocytes were isolated on standard LeuoPREP columns (Becton Dickinson). Adherent monocytes were isolated by incubation at about $37^{\circ} \mathrm{C}$ in DMEM in 24-well Costar cluster dishes for about 1 hour. Nonadherent cells were removed by 3 washes of DMEM. Each culture contained about $1 \times 10^{6}$ monocytes. Triplicate cultures were incubated in DMEM alone (control), DMEM containing $100 \mathrm{ng} / \mathrm{ml}$ LPS, or DMEM plus LPS with 0.1 , 2.0 or $4.0 \mu \mathrm{g} / \mathrm{ml} \mathrm{BMS}-182123$. After incubation at $37^{\circ} \mathrm{C}$ for 2 hours, the culture supernatants were assayed for TNF- $\alpha$ using an ELISA (Endogen) specific for antigenic TNF- $\alpha$.

\section{Northern Blot Analysis of TNF- $\alpha$ Message}

The quantitation of TNF- $\alpha$ messenger RNA was determined using standard laboratory methods ${ }^{18,19)}$. Equal amounts of RNA from each sample were blotted and probed using a ${ }^{32} \mathrm{P}$-labelled probe $\left({ }^{5} \mathrm{GCTGACG}-\right.$ GTGTGGGTGAGGAGCACGTAGTC ${ }^{3^{\prime}}$ ) complementary to murine TNF- $\alpha$ mRNA. Autoradiograms were analyzed in an LKB Ultrascan XL densitometer to establish relative amounts of TNF- $\alpha$ message for each sample. To evaluate LPS induction of TNF- $\alpha$ message, macrophages cultures were incubated with LPS $(1 \mu \mathrm{g} / \mathrm{ml})$ with and without BMS-182123 $(2 \mu \mathrm{g} / \mathrm{ml})$ for 4 hours and the RNA harvested and analysed. To determine the effects of BMS-182123 on TNF- $\alpha$ mRNA stability, the macrophages were first incubated with LPS $(1 \mu \mathrm{g} / \mathrm{ml})$ for 2 hours, the cultures were washed and actinomycin D added $(10 \mu \mathrm{g} / \mathrm{ml})$ to prevent further transcription. Cultures with and without BMS-182123 were prepared and harvested at 30 minute intervals to determine the degradation rate for the TNF- $\alpha$ mRNA.

Purification of BMS-182123

Purification of BMS-182123 from a 250-liter fermentor 
culture of $P$. chrysogenum strain V39673 supplemented with $1 \%$ Amberlite XAD-8 is summarized in Fig. 2.

\section{Results}

Taxonomy

The results on taxonomic studies performed on strain V39673 and by comparison with the published reports ${ }^{20.21)}$ identify this strain as Penicillium chrysogenum. Microscopic examination shows that conidiophores are smooth-walled, arising densely, varying in length and branching below the level of the metulae. Penicilli are asymmetric, branched, bearing 3 to 4 phialides to form a large penicillus. Some penicilli phialides producing long chains of spores tangled or adhering into well defined columns. The conidia are smooth, globose to subglobose ranging in size from 2.5 to $4.0 \mu \mathrm{m}$ in diameter, smooth walled when seen under light microscope with slightly roughed surface when seen under TEM. The colonies on CZAPEK's agar are furrowed in a radial pattern but with a central area sometimes sterile. Colonies are azonate with growing margins flat. Vegetative hyphae are yellowish to cream color becoming blue green when sporulating. Exudate is abundant as golden yellow droplets on young cultures. Colony reverse is bright yellow. No sclerotia are observed. On Malt Extract Agar, growth is slower. The colonies show a looser textured basal felt. They are flat, not furrowed. No exudate is produced and there is no colored pigment diffusing into the surrounding medium. Colony reverse is brownish drab.

Fig. 1. The chromatogram of HPLC analysis of an extract of Penicillium chrysogenum strain V39673.

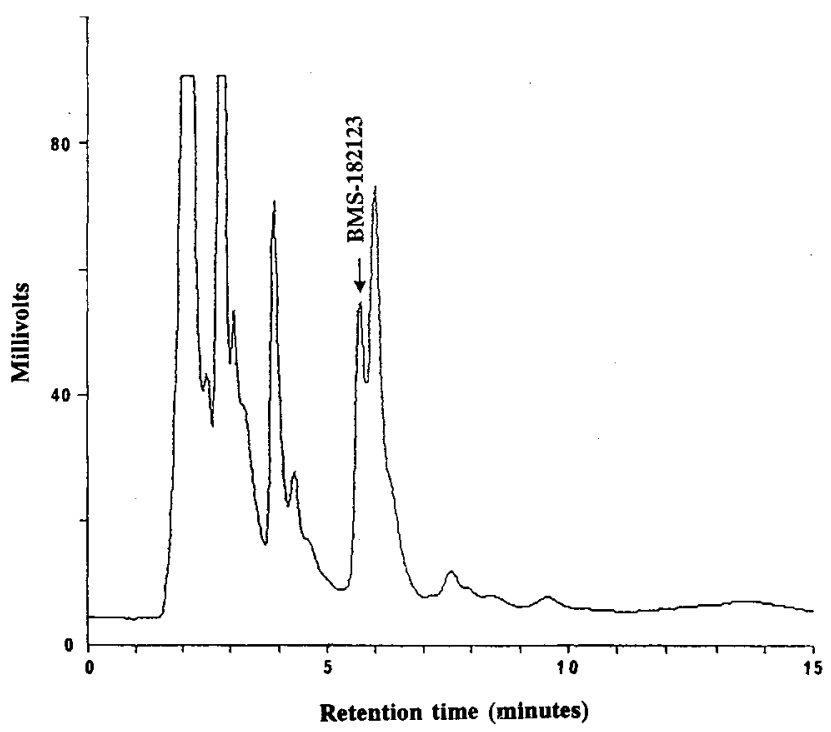

Fermentation

Fig. 1 shows the HPLC analysis of the extract from a 3-day old shake flask culture of strain V39673. The titer of BMS-182123 (retention time: 5.72 minutes) was $15.7 \mu \mathrm{g} / \mathrm{ml}$. The time course of BMS- 182123 production is shown in Table 1. There was a significant drop in the titer of BMS-182123 after 3 days of fermentation. The titer of BMS-182123 dropped from $15.7 \mu \mathrm{g} / \mathrm{ml}$ at day 3 to $0.1 \mu \mathrm{g} / \mathrm{ml}$ at day 5 . It is evident that BMS-182123 was further metabolized and degraded after day 3 of the fermentation. Since addition of hydrophobic resins to the fermentation of several unstable antibiotics led to an increase in production of these secondary metabolites ${ }^{22 \sim 24)}$, the effect of hydrophobic resins on the production of BMS-182123 in the fermentation was examined. Various hydrophobic resins $(1 \%)$ were added to the cultures of strain V39673 at 48 hours of the production cycle and the result is summarized in Table 2. With the exception of Amberlite XAD-2 resin, the production of BMS-182123 in the resin-supplemented cultures was $2.1 \sim 4.0$ fold higher than that of the control culture. Among the 5 resins tested, Amberlite XAD-8 was the best resin in enhancing the production of BMS- 182123 with the titer of $53.7 \mu \mathrm{g} / \mathrm{ml}$. Since the time of addition of resin to the fermentation for titer improvement is also an important factor ${ }^{22,25)}$, Amberlite XAD- 8 resin was added to the fermentation either at 24 , 48 or 72 hours to determine the optimal time of addition and the result is summarized in Table 3. The optimal

Table 1. Time course of BMS-182123 production by Penicillium chrysogenum strain V39673 in shake flask culture.

\begin{tabular}{cc}
\hline Culture age (day) & Titer $(\mu \mathrm{g} / \mathrm{ml})$ \\
\hline 2 & 15.5 \\
3 & 15.7 \\
4 & 3.98 \\
5 & 0.10 \\
\hline
\end{tabular}

Table 2. Effect of various resins on the production of BMS-182123 by Penicillium chrysogenum strain V39673.

\begin{tabular}{lc}
\hline \multicolumn{1}{c}{ Resin $^{\mathrm{a}}$} & BMS-182123 $(\mu \mathrm{g} / \mathrm{ml})$ \\
\hline No addition & 13.5 \\
Amberlite XAD-2 & 2.6 \\
Amberlite XAD-7 & 28.6 \\
Amberlite XAD-8 & 53.7 \\
Amberlite XAD-16 & 42.3 \\
Diaion HP-20 & 35.7 \\
\hline
\end{tabular}

a Resin was added to the culture at 48 hours to yield a final concentration of $1 \%(w / v)$. 
Table 3. Effect of Amberlite XAD-8 (1\%) on the production of BMS- 182123 by Penicillium chrysogenum strain V39673.

\begin{tabular}{cc}
\hline Time of resin addition (hour) & BMS- $182123(\mu \mathrm{g} / \mathrm{ml})$ \\
\hline No addition & 15.7 \\
24 & 86.3 \\
32 & 58.6 \\
48 & 67.0 \\
\hline
\end{tabular}

Fig. 2. The purification scheme of BMS-182123 from a 250-liter fermentor culture of Penicillium chrysogenum strain V39673.

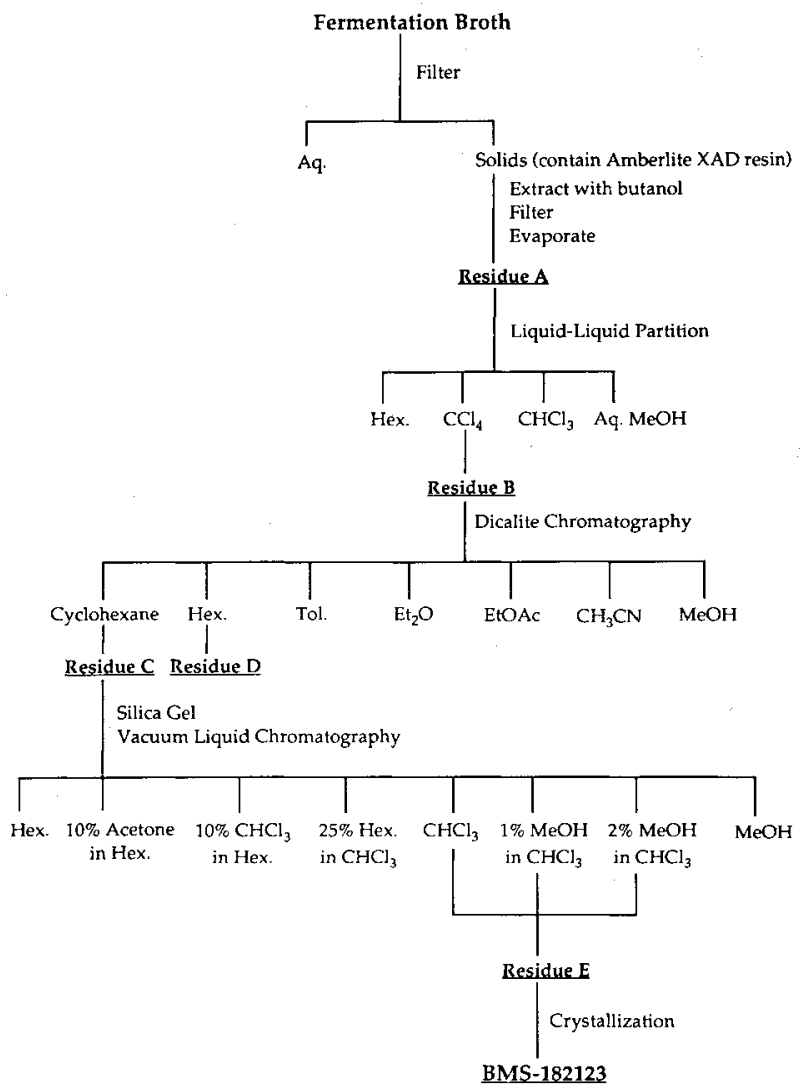

time of addition of Amberlite XAD-8 to the fermentation was at 24 hours, enhancing the titer of BMS- 182123 by 5.5 fold to $86.3 \mu \mathrm{g} / \mathrm{ml}$. When $1 \%$ Amberlite XAD- 8 was added to the fermentor culture at 24 hours, the maximum titer of BMS-182123 achieved was $54.3 \mu \mathrm{g} / \mathrm{ml}$ at day 6 of the fermentation.

\section{Isolation of BMS-182123 from} Fermentor Culture

A 250-liter fermentor culture containing Amberlite XAD-8 (1\%) was harvested and filtered. BMS-182123 was isolated from solids as shown in Fig. 2 either by monitoring the activity on LPS induction of TNF- $\alpha$ from RAW264.7 macrophages or evaluated by TLC (silica gel
Fig. 3. The structure of BMS-182123 (trichodimerol).

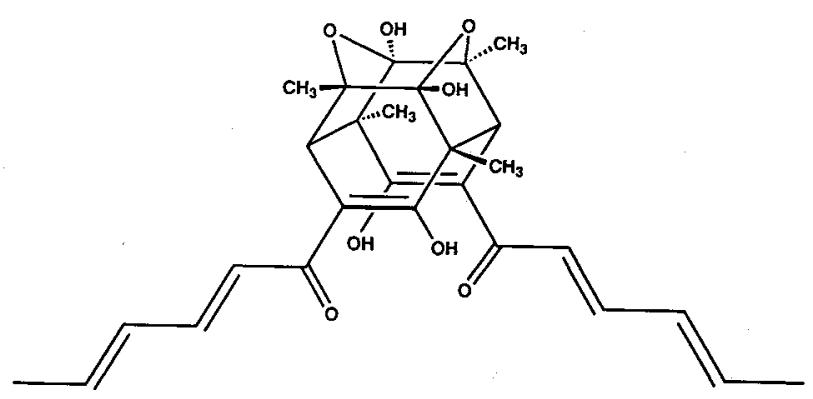

$\left.0.25 \mathrm{~mm}, \mathrm{CHCl}_{3}-\mathrm{CH}_{3} \mathrm{OH} 95: 5\right)$ using short UV light for visualization. The recovered solids were extracted with butanol (57 liters). The butanol extract was evaporated in vacuo to dryness in a rotary evaporator to yield $360 \mathrm{~g}$ residue A. Residue A was dissolved in $1600 \mathrm{ml}$ of $10 \%$ aqueous methanol. The solution was extracted 3 times with hexane $(1000 \mathrm{ml}$ each) and the hexane layer was removed. The remaining aqueous methanol phase was adjusted to $25 \%$ aqueous methanol and extracted 3 times with carbon tetrachloride $(1000 \mathrm{ml}$ each) and a fourth time with $630 \mathrm{ml}$ carbon tetrachloride, which had been previously saturated with $25 \%$ aqueous methanol. The carbon tetrachloride layer was evaporated to dryness in vacuo to yield $68.1 \mathrm{~g}$ residue $\mathrm{B}$ which was enriched in BMS-182123.

Residue B was applied to a $2000-\mathrm{ml}$ fritted filter funnel packed with $350 \mathrm{~g}$ of diatomaceous earth. Elution using in-house vacuum was with cyclohexane followed by hexane, toluene, diethyl ether, ethyl acetate, acetonitrile, and methanol $(1000 \mathrm{ml}$ each). The majority of BMS182123 was located in the cyclohexane fraction (residue $\mathrm{C}, 47.0 \mathrm{~g}$ ) and, hexane and toluene fractions (pooled, residue $\mathrm{D}, 31.4 \mathrm{~g}$ ). Residue $\mathrm{C}$ was further processed by vacuum-liquid chromatography (Merck LiChroprep Silica Gel $2 \sim-40 \mu \mathrm{m}, 350 \mathrm{~g})$. The column $(13 \mathrm{~cm}$ i.d. $\times 17 \mathrm{~cm})$ was eluted with hexane $(500 \mathrm{ml}), 10 \%$ acetone in hexane $(4 \times 500 \mathrm{ml}), 10 \%$ chloroform in hexane $(3 \times 200 \mathrm{ml}), 25 \%$ hexane in chloroform $(2 \times 200$ $\mathrm{ml})$, chloroform $(4 \times 200 \mathrm{ml}), 1 \%$ methanol in chloroform $(200 \mathrm{ml}), 2 \%$ methanol in chloroform $(100 \mathrm{ml})$, and methanol $(2 \times 200 \mathrm{ml})$. BMS-182123 was located in the chloroform, $1 \%$ methanol in chloroform and $2 \%$ methanol in chloroform fractions. These fractions were pooled and evaporated to dryness in vacuo to yield $2.57 \mathrm{~g}$ of residue E. Upon recrystallization in hexane-chloroform - methanol (1:1:1), $577 \mathrm{mg}$ of pure BMS-182123 was recovered. The spectroscopic data of BMS-182123 
were in full agreement with those published for trichodimerol, a metabolite isolated from Trichoderma longibrachiatum $^{26)}$. Furthermore, the structure of BMS182123 was confirmed by an X-ray crystallographic study $^{27)}$. No biological activities have been reported for trichodimerol. The structure of BMS-182123 (trichodimerol) is shown in Fig. 3.

\section{Biological Activities}

BMS-182123 was tested in vitro for its ability to inhibit bacterial LPS induction and secretion of cytokine, $\mathrm{TNF}-\alpha$, from murine macrophages and human peripheral blood monocytes. The results are summarized in Figs. $4 \sim 6$. In the absence of LPS, the RAW macrophages did not secrete detectable levels of TNF- $\alpha$ (Fig. 4). LPS induced levels of TNF- $\alpha$ in the absence of BMS-182123 were used as the maxima. The highest concentrations of drug resulted in $>99 \%$ inhibition of LPS induced TNF- $\alpha$ (Fig. 4). In these studies the effective BMS-182123 concentration $\left(\mathrm{IC}_{50}\right)$ resulting in $50 \%$ inhibition of LPS-induced TNF- $\alpha$ was about $600 \mathrm{ng} / \mathrm{ml}$. To verify that the compound was also active with native macrophages, cultures were established using murine peritoneal

Fig. 4. The effect of BMS-182123 on the LPS induction of TNF- $\alpha$ from murine RAW 264.7 macrophages $(\bullet)$ and thioglycolate elicited murine peritoneal macrophages $(\boldsymbol{\square})$.

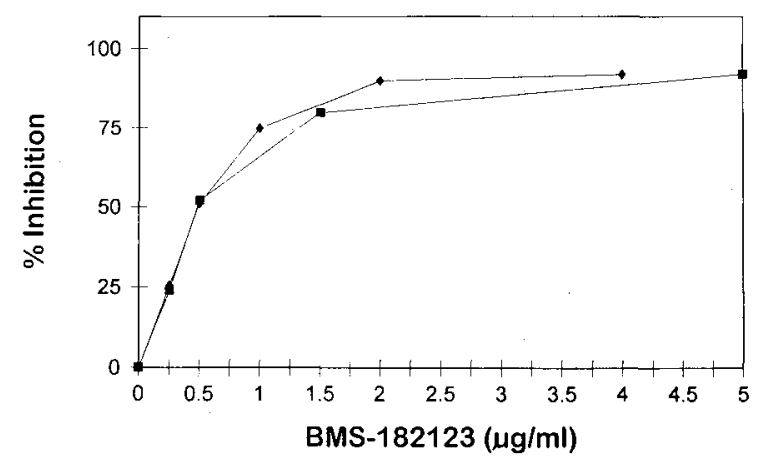

Fig. 5. The effect of BMS-182123 on the LPS induction of TNF- $\alpha$ from human peripheral blood monocytes.

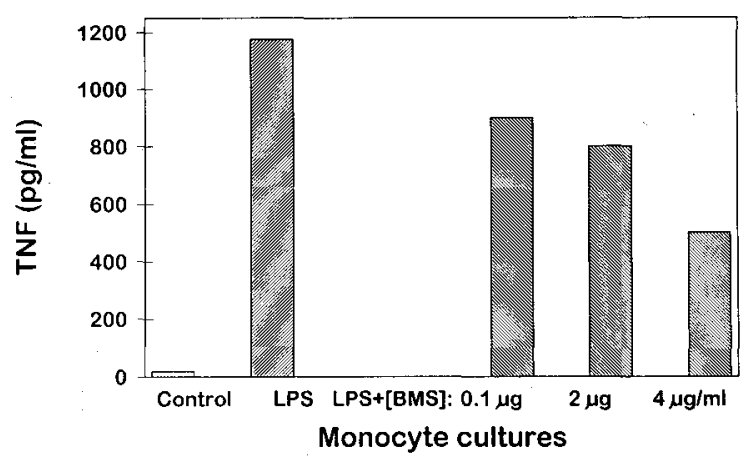

macrophages (thioglycolate-elicited) and the result is summarized in Fig. 4. As seen with the RAW macrophages, BMS-182123 inhibited LPS induction of TNF- $\alpha$ in the native murine macrophages. The $\mathrm{IC}_{50}$ under these assay conditions was about $500 \mathrm{ng} / \mathrm{ml}$. The effect of BMS-182123 on the secretion of TNF- $\alpha$ by human peripheral blood monocytes stimulated by LPS is shown in Fig. 5. BMS-182123 suppressed LPS induction of $\mathrm{TNF}-\alpha$ in the human monocytes with an $\mathrm{IC}_{50}$ of about $4.0 \mu \mathrm{g} / \mathrm{ml}$. Thus with both a continuous macrophages cell line, native murine peritoneal macrophages and human blood monocytes cultured in vitro, BMS-182123 was effective and demonstrated a concentration dependent inhibition of LPS induced TNF- $\alpha$ secretion.

These studies demonstrate the ability of BMS-182123 to suppress LPS induction of TNF- $\alpha$ protein. To help establish the level at which the compound interferes in LPS induction of TNF- $\alpha$, BMS-182123 was tested in the human TNF- $\alpha$ promoter based assay. A concentration dependent suppression of LPS-induced promoter activity was observed (Fig. 6) with an $\mathrm{IC}_{50}$ value of approximately $200 \mathrm{ng} / \mathrm{ml}$. To verify suppression of

Fig. 6. The effect of BMS-182123 on the LPS induction of human TNF- $\alpha$ promoter activity.

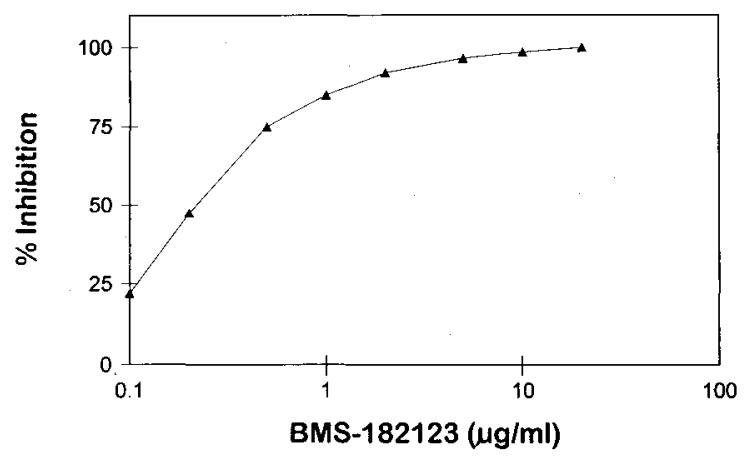

Fig. 7. The effect of BMS-182123 on the LPS induction of TNF- $\alpha$ mRNA from macrophage.

Solid bar: no BMS-182123. Shaded bar: $2 \mu \mathrm{g} / \mathrm{ml}$ BMS182123.

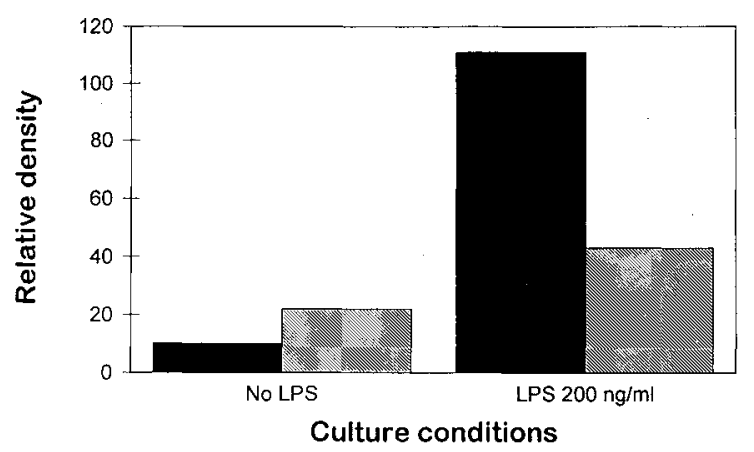


Fig. 8. The effect of BMS-182123 on the stability of TNF- $\alpha$ mRNA.

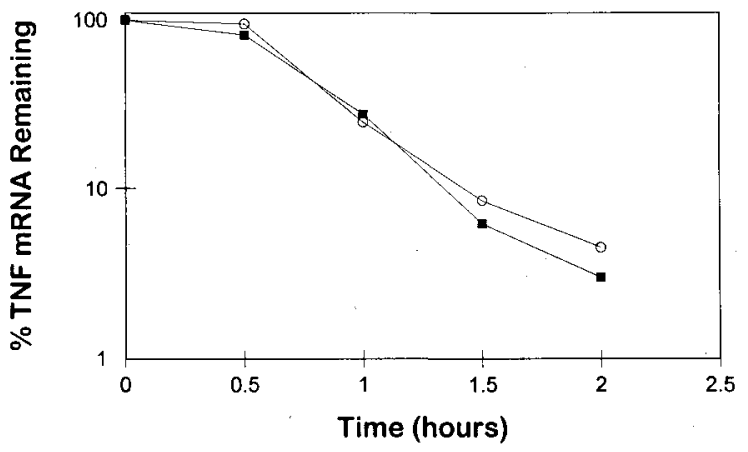

TNF- $\alpha$ promoter activity, levels of TNF- $\alpha$ messenger RNA in the macrophages cultures were probed by Northern analysis (Fig. 7). Based on these results, it is clear that BMS-182123 at a concentration of $2 \mu \mathrm{g} / \mathrm{ml}$ significantly reduces the steady-state TNF- $\alpha$ mRNA expression induced by LPS. To determine if this decreased mRNA expression was caused by an increase in the post-transcriptional degradation, studies were performed in which the compound was not added to the cells until after mRNA levels were induced by LPS treatment. From these studies (Fig. 8), there does not appear to be any changes in mRNA stability associated with the addition of BMS-182123 to the macrophages cultures. Thus, under these assay conditions, BMS182123 does in fact appear to inhibit TNF- $\alpha$ gene transcription and not to alter post-transcriptional events.

\section{Discussion}

In this paper we described the fermentation and isolation of a metabolite from $P$. chrysogenum strain V39673, BMS-182123, which demonstrated in vitro inhibitory activity on the production of LPS-induced TNF- $\alpha$ from murine macrophages and human monocytes. Therefore BMS-182123 may be a potential candidate for development as an agent for treatment of septic shock and other TNF- $\alpha$ mediated pathophysiologic diseases. The structure of BMS-182123 is identical to trichodimerol which was isolated from $T$. longibrachiatum $^{26)}$. No biological activities have been reported for trichodimerol. The production of TNF- $\alpha$ can be regulated at many levels. Increased transcription accounts for a significant portion of the LPS induction of TNF- $\alpha$ production; however, LPS also dramatically affects posttranscriptional control of mRNA abundance. From these studies, it is evident that BMS-182123 results in a significant suppression of TNF- $\alpha$ protein apparently due to a decrease in gene transcription. This is supported by the observed suppression of the TNF- $\alpha$ promoter based assays, and the decrease in TNF- $\alpha$ mRNA steady state levels without any changes in the apparent mRNA stability. The exact site of action where the drug intercedes to interrupt TNF- $\alpha$ gene transcription remains to be determined. In addition BMS-182123, at a concentration of $4 \mu \mathrm{g} / \mathrm{ml}$, did not show any nonspecific effects on protein synthesis as demonstrated by macrophages incorporation of ${ }^{35} \mathrm{~S}$-methionine (over 2 hours) into acid precipitable protein, or constitutive secretion of lysozyme over a 24 hours period (data not shown). Therefore the inhibitory effect of BMS-182123 on the production of TNF- $\alpha$ is not due to nonspecific effects on cell functions. LPS induced interleukin- $1 \beta$ (IL-1 $\beta$ ) secretion over a 4 hour interval was not abolished but was reduced by 25 to $50 \%$ (data not shown). Thus, there may be some cross over in transduction signals between IL- $1 \beta$ and TNF- $\alpha$ which are blocked by BMS182123 , or this may merely reflect a reduction in autocrine induction of IL- $1 \beta$ by the macrophages' TNF- $\alpha$. Whether or not BMS-182123 suppresses TNF- $\alpha$ induction by stimuli other than LPS remains to be determined.

Addition of resin to the fermentation not only enhanced the production of BMS-182123 but also provided an effective way for its scale-up production and purification. Before the studies of the effect of resin on the production of BMS-182123, the downstream processing from the fermentor culture was hindered by the presence of antifoam agents. Polypropylene glycol P-2000 was found to be very effective in controlling the foaming in the fermentation of strain V39673. For a 10-liter fermentor cultivation of V39673, 30 40 ml polypropylene glycol was needed to suppress the foaming for the whole fermentation run. Polypropylene glycol has a similar polarity to BMS- 182123 and coupled to the low productivity in the fermentation, a very low recovery yield was obtained in the fermentor culture. Shifting to a more non-polar silicone-based antifoam agent Antifoam C Emulsion (Dow Corning) was attempted to aid the chromatographic separation of BMS-182123 from the silicone emulsion, however, the silicone emulsion was ineffective in controlling the foaming in the fermentation. Significant amounts of silicone emulsion $(350 \sim 400 \mathrm{ml})$ were required to suppress the foaming in the 10-liter fermentor culture of strain V39673. Addition of such a large amount of antifoam led to a decrease in the production of BMS-182123 and also presented a problem in removing such a large quantity of silicone emulsion in the downstream processing step. With addition of Amberlite XAD-8 (1\%) to the fermentor culture at 24 hours, the maximum titer of $54.3 \mu \mathrm{g} / \mathrm{ml}$ was achieved. By binding BMS- 182123 to the resin, a large portion of polypropylene glycol present in the fermentation can be removed before the extraction step and together with the increase in the production of BMS-182123 in the resinsupplemented fermentor culture (i.e. significant increase in ratio of BMS-182123 to polypropylene glycol), polypropylene glycol can be removed from BMS-182123 by 
subsequent chromatographic separation. A large scale fermentation process can now be carried out to obtain large quantities of BMS-182123 for expanded biological evaluation.

\section{References}

1) Mannel, D. N.; R. N. Moore \& S. E. Mergenhagen: Macrophages as a source of tumoricidal activity (tumor necrotizing factor). Infect. Immun. 30: 523 530, 1980

2) Nissen-Meyer, J. \& J. Hammerstrom: Physicochemical characterization of cytostatic factors released from human monocytes. Infect. Immun. 38: 67 72, 1982

3) Lasfargues, A. \& R. Charby: Endotoxin-induced tumor necrosis factor (TNF): selective triggering of TNF and interleukin-1 production by distinct glucosamine-derived lipids. Cell. Immunol. 115: 165 178, 1986

4) Henter, I.-T.; O. SOdor \& U. Anderson: Identification of individual tumor necrosis factor/cachetin-producing cells after lipopolysaccharide induction. Eur. J. Immunol. 18: $983 \sim 988,1988$

5) Girorr, B. P. \& B. BEUlter: Effect of amrinone on tumor necrosis factor production in endotoxic shock. Cir. Shock 36: $200 \sim 207,1992$

6) Tracey, K. J.; Y. Fong, D. G. Hesse, K. R. Manogue, A. T. Lee, G. C. Kuo, S. F. Lowry \& A. Cerami: Anti-cachectin/TNF monoclonal antibiodies prevent septic shock during lethal bacteraemia. Nature 330: 662 664, 1987

7) Damas, P.; A. Reuter, P. Gysen, J. Demonty, M. Lamy \& P. Franchimont: Tumor necrosis factor and interleukin-1 serum levels during severe sepsis in humans. Crit. Care Med. 17: 975 978, 1989

8) Beutler, B.; I. W. Milsark \& A. Cerami: Passive immunization against cachectin/tumor necrosis factor protects mice from lethal effect of endotoxin. Science 229: $869 \sim 871,1985$

9) Hinshaw, L. B.; P. Tekamp-Olson \& A. C. K. Chang: Survival of primates in $\mathrm{LD}_{100}$ septic shock following therapy with antibody to tumor necrosis factor $\left(\mathrm{TNF}_{\alpha}\right)$. Cir. Shock 30: 279 292, 1990

10) Morrison, D. C.; C. A. Dinarello, R. S. Munford, C. Natanson, R. Danner, M. Pollack, J. J. Spitzer, R. J. Ulevitch, S. N. Vogel \& E. McSweEgan: Current status of bacterial endotoxins. ASM News 60: $479 \sim 484$, 1994

11) Glausen, M. P.; D. Heumann, J. D. Baumgartner \& J. CoHEN: Pathogenesis and potential strategies for prevention and treatment of septic shock: An update. Clin. Infect. Dis. 18 (Suppl. 2): 205 216, 1994

12) Pennington, J.: TNF: Therapeutic target in patients with sepsis. ASM News 58: 479 482, 1992

13) Smith, E. F. III; M. J. Slivjak, J. O. Bartus \& K. M. ESSER: SK \& F 86002 inhibits tumor necrosis factor formation and improves survival in endotoxemic rats. $\mathbf{J}$. Cardiovasc. Pharmacol. 18: 721 728, 1991
14) Economou, J. S.; K. Rhoades, R. Essner, W. H. MCBRIDE, J. C. Gasson \& D. L. Morton: Genetic analysis of human tumor necrosis factor $\alpha /$ cachectin promoter region in a macrophage cell line. J. Exp. Med. 170: $321 \sim 326,1989$

15) Lynch, M. J.; L. Pelosi, J. M. Carboni, J. Merwin, K. Coleman, R. R. C. Wang, P. F. M. Lin, D. L. Henry \& M. G. BRattain: Transforming growth factor- $\beta 1$ induces transforming growth factor- $\alpha$ promoter activity and transforming growth factor- $\alpha$ secretion in the human colon adenocarcinoma cell line FET. Cancer Res. 53: $4041 \sim 4047,1993$

16) Kiener, P. A.; F. Marek, G. Rodgers, P. F. Lin, G. WARR \& J. DESIDERIO: Induction of tumor necrosis factor, IFN- $\gamma$, an acute lethality in mice by toxic and non-toxic forms of lipid A. J. Immunol. 141: 870 874, 1988

17) Grove, R. I.; N. J. Allegretto, P. A. Kiener \& G. A. WARR: Lipopolysaccharide (LPS) alters phosphatidylcholine metabolism in elicited peritoneal macrophages. $\mathbf{J}$. Leukocyte Biol. 48: 38 42, 1990

18) Chomczynski, P. \& N. SACchi: Single-step method of RNA isolation by acid guanidium thiocyantate-phenolchloroform extraction. Anal. Biochem. 162: 156 159, 1987

19) Henderson, G. S.; J. T. Conary, J. M. Davidson, S. J. Stewart, F. S. House \& T. L. MCCurley: A reliable method for northern blot analysis using synthetic oligonucleotide probes. BioTechniques 10: 190 197, 1991

20) RAPER, K. \& C. THOM: In Mamual of the Penicillia, Williams and Wilkins Co., 1949

21) Ramirez, C.: In Manual and Atlas of the Penicillia, Elsevier Biomedical, 1982

22) Marshall, V. P.; S. J. McWethy, J. M. Sirotti \& J. I. Ciaidella: The effect of neutral resins on the fermentation production of rubradirin. J. Ind. Microbiol. 5: 283 288, 1990

23) Lam, K. S.; D. R. Gusta vson, J. A. Veitch \& S. Forenza: The effect of cerulenin on the production of esperamicin $\mathrm{A}_{1}$ by Actinomadura verrucosospora. J. Ind. Microbiol. 12: $99 \sim 102,1993$

24) Gerth, K.; N. Bedorf, H. IrschiK, G. Hofle \& H. REICHENBACH: The soraphens: A family of novel antifungal compounds from Sorangium cellulosum (Myxobacteria). I. Soraphen $\mathrm{A}_{1 \alpha}$ : Fermentation, isolation, biological properties. J. Antibiotics 47: 23 31, 1994

25) Jarvis, B. B.; C. A. Armstrong \& M. ZENG: Use of resins for trichothecene production in liquid cultures. $J$. Antibiotics 43: $1502 \sim 1504,1990$

26) Andrade, R.; W. A. Ayer \& P. P. Mebe: The metabolites of Trichoderma longibrachiatum. Part I. Isolation of the metabolites and the structure of trichodimerol. Can. J. Chem. 70: 2526 2535, 1992

27) Gao, Q.; J. E. Leet, S. T. Thomas, J. A. Matson \& D. P. BRanCROFT: Crystal structure of trichodimerol. J. Nat. Prod. 58: 1817 1821, 1995 